\title{
Effects of Rosuvastatin and Atorvastatin on Renal Function
}

\author{
- Meta-Analysis -
}

Yongxia Wu, MD; Yan Wang, MD; Chuankai An, BSc; Zhe Dong, MD, PhD; Hui Liu, MD; Yun Zhang, MD, PhD; Mingxiang Zhang, MD, PhD; Fengshuang An, MD, PhD

\begin{abstract}
Background: Several clinical trials have reported inconsistent findings for the effects of rosuvastatin (RSV) and atorvastatin (ATV) on renal function. The aim of this meta-analysis was to investigate the effects of these 2 statins on glomerular filtration rate (GFR) and proteinuria respectively, and determine which is better.
\end{abstract}

Methods and Results: PubMed, CENTRAL, Web of Knowledge, and ClinicalTrials.gov website were searched for randomized controlled trials. Eligible studies reported GFR and/or proteinuria during treatment with RSV or ATV compared with control (placebo, no statins, or usual care), or RSV compared with ATV head to head. Trials that enrolled dialysis participants and teenagers were excluded. Statistical heterogeneity was assessed using the $\mathrm{I}^{2}$ statistic, and pooled results using the random-effects model. The standardized mean differences (SMD) and ratio of means (ROM) were measured, respectively, to analyze GFR and proteinuria. Sixteen trials with a total number of 24,278 participants were identified. Compared with control, changes in the SMD of GFR were 0.04 (95\% confidence interval [Cl]: 0.01-0.07) and $0.59(95 \% \mathrm{Cl}: 0.12-1.06)$ for RSV and ATV, respectively. The ROMs of proteinuria were 0.59 (95\%Cl: $0.46-0.74)$ for RSV vs. the control group, and 1.23 (95\%Cl: $1.05-1.43)$ in the head-to-head comparison.

Conclusions: Both RSV and ATV improve GFR, and ATV seems to be more effective in reducing proteinuria. The validity and clinical significance require high-quality intensive studies with composite clinic endpoints of kidney and death. (Circ J 2012; 76: 1259-1266)

Key Words: Atorvastatin; Glomerular filtration rate; Proteinuria; Rosuvastatin

C hronic kidney disease (CKD) and renal replacement treatment are important global public health problems associated with a high risk of cardiovascular disease (CVD) and high health-care costs. ${ }^{1,2}$ Dyslipidemia is one of the risk factors (the others are hypertension, diabetes, and smoking) associated with the development and progression of CKD ${ }^{3,4}$ Clinical trials have indicated the powerful effects of 3-hydroxy-3-methylglutaryl coenzyme A reductase inhibitors (statins) on lipid lowering, which is independently associated with the decrease of all cause mortality and cardiovascular mortality. ${ }^{5,6}$ Several studies and meta-analyses have shown the renoprotective effects of statins. ${ }^{7-12}$ The roles of 2 strong statins (rosuvastatin [RSV] and atorvastatin [ATV]) on renal function, however, still need to be clarified considering the conflicting results.

In the PLANET 1 and PLANET 2 trials, diabetic and non- diabetic patients with moderate proteinuria were assigned to RSV or ATV for 1 year. ${ }^{13,14}$ It was found that ATV significantly reduced proteinuria without affecting glomerular filtration rate (GFR), whereas RSV was associated with a significant decline in GFR and had no effect on proteinuria. In contrast, Abe et al reported that RSV reduced proteinuria significantly in patients with diabetic nephropathy, ${ }^{15}$ and another study by Sawara et al showed that RSV had beneficial roles both on GFR and proteinuria in CKD patients. ${ }^{16}$ The previous meta-analysis by Sandhu et al reported significant decrease in the rate of GFR reduction by a mean of $1.22 \mathrm{ml}$. $\mathrm{min}^{-1}$. year-1 and meta-regression showed that ATV was associated with a significantly larger beneficial effect on the rate of decline in GFR than other statins. ${ }^{9}$ A Cochrane systematic review by Navaneethan et al, however, showed that statins did not improve the decline in renal function as measured by cre-

Received November 29, 2011; revised manuscript received January 13, 2012; accepted January 17, 2012; released online March 1, 2012 Time for primary review: 14 days

Key Laboratory of Cardiovascular Remodeling and Function Research, Chinese Ministry of Education and Chinese Ministry of Health, Shandong University Qilu Hospital, Jinan (Y. Wu, Y. Wang, Z.D., H.L., Y.Z., M.Z., F.A.), Shandong; School of Electronics Engineering and Computer Science, Peking University, Beijing (C.A.), China

The first two authors contributed equally to this work (Y. Wu, Y. Wang).

Mailing address: Fengshuang An, MD, PhD or Mingxiang Zhang, MD, PhD, Shandong University Qilu Hospital, Jinan, No.107, Wen Hua Xi Road, Jinan, Shandong, 250012, P.R. China. E-mail: anfengshuang@hotmail.com or zhangmingxiang@sdu.edu.cn

ISSN-1346-9843 doi:10.1253/circj.CJ-11-1385

All rights are reserved to the Japanese Circulation Society. For permissions, please e-mail: cj@j-circ.or.jp 


\section{8 potential relevant articles identified}

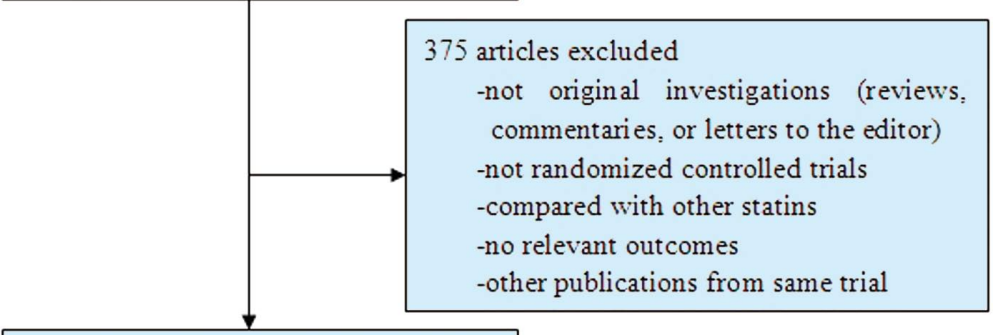

33 randomized controlled trials of RSV and or ATV identified

$\longrightarrow$\begin{tabular}{l|}
17 articles excluded \\
-no relevant outcomes \\
-enrolled dialysis patients \\
-with participants younger than 18 years \\
-high-dose versus low-dose statins trials
\end{tabular}

16 included in analysis

4 compared RSV with control

7 compared ATV with control

5 compared RSV with ATV
Figure 1. Flow diagram of the trial selection process. ATV, atorvastatin; RSV, rosuvastatin.

\begin{tabular}{|c|c|c|c|c|c|c|c|}
\hline Study & Year & Country & Subjects & $\begin{array}{c}\text { Sample } \\
\text { size }\end{array}$ & $\begin{array}{l}\text { Follow-up } \\
\text { (months) }\end{array}$ & $\begin{array}{l}\text { Lost to } \\
\text { follow-up (\%) }\end{array}$ & Blinding \\
\hline Abe et $\mathrm{al}^{15}$ & 2011 & Japan & $\begin{array}{c}\text { Diabetic } \\
\text { nephropathy }\end{array}$ & 104 & 6 & 3 & Open-label \\
\hline JUPITER ${ }^{23}$ & 2011 & USA & $\begin{array}{c}\text { Healthy } \\
\text { adult and HTN }\end{array}$ & 16,279 & 12 & NR & Double-blind \\
\hline Sawara et al ${ }^{16}$ & 2008 & Japan & CKD & 38 & 12 & 0 & Open-label \\
\hline Verma et $\mathrm{al}^{24}$ & 2005 & USA & CKD & 91 & 5 & 9 & Open-label \\
\hline ALLIANCE $^{25}$ & 2009 & USA & CVD & 2,442 & 24 & 21 & Open-label \\
\hline Bianchi et $a^{26}$ & 2003 & Italy & CKD & 56 & 12 & NR & Open-label \\
\hline CARDS $^{27}$ & 2009 & UK & $\mathrm{DM}$ & 2,313 & 46.8 & 18 & Double-blind \\
\hline Dalla et al ${ }^{28}$ & 2003 & Italy & $\mathrm{DM}$ & 25 & 12 & 0 & Open-label \\
\hline Goicoechea et al ${ }^{29}$ & 2006 & Spain & CKD & 66 & 6 & 5 & Open label \\
\hline GREACE $^{30}$ & 2004 & Greece & CVD & 1,486 & 48 & NR & Open label \\
\hline LORD $^{31}$ & 2010 & Australia & CKD & 132 & 30 & 7 & Double-blind \\
\hline ATOROS ${ }^{32}$ & 2006 & Greece & $\begin{array}{c}\text { Relatively } \\
\text { healthy adults }\end{array}$ & 120 & 6 & 0 & Open-label \\
\hline PATROL $^{33}$ & 2011 & Japan & Hyperlipidemia & 192 & 4 & 0 & Open-label \\
\hline PLANET1 ${ }^{13}$ & 2010 & USA & $\begin{array}{c}\text { DM with } \\
\text { proteinuria }\end{array}$ & 353 & 12 & 21.8 & Double-blind \\
\hline PLANET2 $^{14}$ & 2010 & USA & $\begin{array}{l}\text { Non-DM with } \\
\text { proteinuria }\end{array}$ & 237 & 12 & 20.3 & Double-blind \\
\hline URANUS ${ }^{34}$ & 2006 & Sweden & $\begin{array}{c}\text { DM with } \\
\text { hyperlipidemia }\end{array}$ & 344 & 4 & NR & Double-blind \\
\hline
\end{tabular}

HTN, hypertension; NR, not reported; CKD, chronic kidney disease; CVD, cardiovascular disease; DM, diabetes mellitus.

atinine clearance, but may decrease urinary protein excretion (UPE). ${ }^{12}$ To resolve the uncertainty, we performed this metaanalysis to address 2 issues: whether RSV and ATV have renoprotective effects on the parameters of GFR and proteinuria; and which is better.

\section{Methods}

Data Source, Search Strategy and Selection Criteria

We searched PubMed, Cochrane Central Register of controlled Trials (CENTRAL), Web of Knowledge, and the ClinicalTrials.gov website for all relevant studies published in 


\begin{tabular}{|c|c|c|c|c|c|c|}
\hline Study (year) & Intervention & $\begin{array}{c}\text { Age } \\
\text { (years) }\end{array}$ & $\begin{array}{l}\text { Baseline cholesterol } \\
\text { (mmol/L), } \\
(\text { mean } \pm \text { SD) }\end{array}$ & $\begin{array}{l}\text { Baseline GFR } \\
\text { (ml/min), } \\
\text { (mean } \pm \text { SD) }\end{array}$ & $\begin{array}{c}\text { Baseline ACR } \\
(\mathrm{mg} / \mathrm{g}), \\
(\text { mean } \pm \text { SD) }\end{array}$ & $\begin{array}{l}\text { Baseline } \\
\text { UPE }^{\ddagger}(\mathrm{mg} / \mathrm{d})\end{array}$ \\
\hline \multirow[t]{2}{*}{ Abe et al ${ }^{15}(2011)$} & RSV $2.5-10 \mathrm{mg}$ & 65 & $5.87 \pm 0.59$ & $70.4 \pm 11.9$ & $141 \pm 86$ & NR \\
\hline & Usual care & 65 & $5.79 \pm 0.65$ & $69.3 \pm 9.50$ & $142 \pm 83$ & NR \\
\hline \multirow[t]{2}{*}{ JUPITER ${ }^{23}$ (2011) } & RSV $20 \mathrm{mg}$ & 66 & NR & $75.4 \pm 17.5$ & $N R$ & NR \\
\hline & Placebo & 66 & NR & $75.4 \pm 17.1$ & NR & NR \\
\hline \multirow[t]{2}{*}{ Sawara et al ${ }^{16}(2008)$} & RSV $2.5 \mathrm{mg}$ & 64 & $5.91 \pm 1.23$ & $50.7 \pm 18.7$ & NR & $170 \pm 290$ \\
\hline & No statins & 67 & $5.31 \pm 0.73$ & $57.3 \pm 16.2$ & NR & $120 \pm 300$ \\
\hline \multirow[t]{2}{*}{ Verma et $\mathrm{al}^{24}$ (2005) } & RSV $10 \mathrm{mg}$ & 73 & $5.79 \pm 1.58$ & $42.3 \pm 11.1$ & NR & NR \\
\hline & No statins & 74 & $5.25 \pm 0.88$ & $49.4 \pm 11.9$ & NR & NR \\
\hline \multirow[t]{2}{*}{ ALLIANCE $^{25}$ (2009) } & ATV $10-80 \mathrm{mg}$ & 61 & NR & $73.0 \pm 17.8$ & NR & NR \\
\hline & Usual care & 61 & NR & $72.6 \pm 17.9$ & NR & NR \\
\hline \multirow[t]{2}{*}{ Bianchi et al ${ }^{26}$ (2003) } & ATV $10-40 \mathrm{mg}$ & 57 & $8.14 \pm 0.16$ & $50.8 \pm 1.8$ & NR & $2,500 \pm 1,850$ \\
\hline & No statins & 57 & $7.91 \pm 0.08$ & $50.0 \pm 1.9$ & NR & $1,900 \pm 1,410$ \\
\hline \multirow[t]{2}{*}{ CARDS $^{27}$ (2009) } & ATV $10 \mathrm{mg}$ & 62 & $5.35 \pm 0.83$ & $64.3 \pm 10.3$ & $10.1 \pm 13.9$ & NR \\
\hline & Placebo & 62 & $5.33 \pm 0.80$ & $64.1 \pm 10.3$ & $9.4 \pm 15.7$ & NR \\
\hline \multirow[t]{2}{*}{ Dalla et $\mathrm{al}^{28}(2003)$} & ATV $10 \mathrm{mg}$ & 66 & $6.10 \pm 1.37$ & NR & NR & $5.8 \pm 16$ \\
\hline & Placebo & 63 & $5.25 \pm 0.70$ & NR & NR & $7.2 \pm 11.74$ \\
\hline \multirow[t]{2}{*}{ Goicoechea et al ${ }^{29}(2006)$} & ATV $20 \mathrm{mg}$ & 66 & $5.93 \pm 0.64$ & $42.8 \pm 24.9$ & NR & NR \\
\hline & No statins & 70 & $5.73 \pm 0.96$ & $44.2 \pm 25.9$ & NR & NR \\
\hline \multirow[t]{2}{*}{ GREACE $^{30}(2004)$} & ATV $10-80 \mathrm{mg}$ & 58 & NR & $76 \pm 13$ & NR & NR \\
\hline & Usual care & 58 & NR & $77 \pm 10$ & NR & NR \\
\hline \multirow[t]{2}{*}{ LORD $^{31}$ (2010) } & ATV $10 \mathrm{mg}$ & 60 & $5.42 \pm 1.20$ & $31.9 \pm 11.0$ & NR & $1,430 \pm 2,280$ \\
\hline & Placebo & 60 & $5.75 \pm 1.50$ & $29.1 \pm 12.8$ & $\mathrm{NR}$ & $1,180 \pm 1,610$ \\
\hline \multirow[t]{2}{*}{ ATOROS $^{32}$ (2006) } & RSV $10-20 \mathrm{mg}$ & 54 & $7.37 \pm 0.78$ & $85 \pm 26$ & $70 \pm 40^{\dagger}$ & NR \\
\hline & ATV $20-40 \mathrm{mg}$ & 53 & $7.37 \pm 1.11$ & $85 \pm 20$ & $70 \pm 40^{\dagger}$ & NR \\
\hline \multirow[t]{2}{*}{ PATROL $^{33}$ (2011) } & RSV $2.5-5 \mathrm{mg}$ & 62 & NR & $73.1 \pm 16.2$ & $52.7 \pm 250$ & NR \\
\hline & ATV $10-20 \mathrm{mg}$ & 62 & NR & $75.7 \pm 13.8$ & $82.3 \pm 443$ & NR \\
\hline \multirow[t]{2}{*}{ PLANET113 (2010) } & RSV $10-40 \mathrm{mg}$ & NR & NR & $70.8 \pm 25.0$ & $1,059 \pm 726.8$ & NR \\
\hline & ATV $80 \mathrm{mg}$ & NR & NR & $72.2 \pm 24.9$ & $1,143.2 \pm 779.5$ & NR \\
\hline \multirow[t]{2}{*}{ PLANET2 $^{14}(2010)$} & RSV $10-40 \mathrm{mg}$ & NR & NR & $77.5 \pm 29.3$ & $1,102.7 \pm 804$ & NR \\
\hline & ATV $80 \mathrm{mg}$ & NR & $\mathrm{NR}$ & $71.5 \pm 30.0$ & $1,069.1 \pm 720.8$ & NR \\
\hline \multirow[t]{2}{*}{ URANUS 34 (2006) } & RSV $10-40 \mathrm{mg}$ & 64 & $6.20 \pm 0.89$ & $73.9 \pm 13.8$ & NR & $44.9 \pm 159.8$ \\
\hline & ATV $10-80 \mathrm{mg}$ & 66 & $6.22 \pm 0.91$ & $76.2 \pm 13.2$ & NR & $39.6 \pm 224.6$ \\
\hline
\end{tabular}

†PCR, not ACR, measured. $¥ A$ All the data extracted were measured by UPE; UAE was not measured.

GFR, glomerular filtration rate; ACR, albumin-to-creatinine ratio; UPE, urinary protein excretion; RSV, rosuvastatin; NR, not reported; ATV, atorvastatin; PCR, protein-to-creatinine ratio; UAE, urinary albumin excretion.

English between 1966 and June 2011 using the search items proteinuria, UPE, albuminuria, urinary albumin excretion (UAE), renal function, GFR, kidney disease, RSV, and ATV. We limited our search to randomized controlled trials in adults $>18$ years.

We had a standard approach to the study search, data extraction, and quality assessment, which were undertaken independently by 2 authors (Y. Wu and Y. Wang). Disagreements were resolved by discussion and/or consultation with a third reviewer (F. An). Included studies met the following criteria: (1) prospective, randomized, controlled; (2) compared RSV with control (placebo, no statins or usual care); compared ATV with control (placebo, no statins or usual care); compared RSV with ATV head-to-head; and (3) provided baseline and followup data on GFR measured by creatinine clearance or estimated GFR (eGFR; using the formula of Modification of Diet in Renal Disease Study Group or Cockroft-Gault); proteinuria and/or albuminuria measured on 24-h urine collection or urinary albumin-to-creatinine ratio (ACR). We excluded studies in which the participants were $<18$ years old, and we also excluded studies that enrolled dialysis patients.

\section{Data Extraction and Quality Assessment}

Published reports with full text were obtained for all included studies except 2 trials from the ClinicalTrials.gov website. ${ }^{13,14}$ Two reviewers (Y. Wu and Y. Wang), independently extracted and recorded the following information: study characteristics (year, country, sample size, loss to follow-up, blinding), participants (age, clinical population, baseline data for total cholesterol, GFR, UPE, UAE, protein-to-creatinine ratio [PCR], ACR), intervention (doses of RSV and ATV, duration of follow-up), outcomes (follow-up data of GFR, UPE, UAE, PCR, and ACR).

Study quality was assessed using the Cochrane collaboration's tool for assessing risk of bias (adequate sequence generation, allocation concealment, blinding, incomplete data addressed, free of selective reporting and free of other bias). ${ }^{17}$

\section{Statistical Analysis}

We measured change in the standardized mean differences (SMD) of GFR from baseline to follow-up. When data for change from baseline were available in the included trials, we directly extracted them from the literature. When only base- 


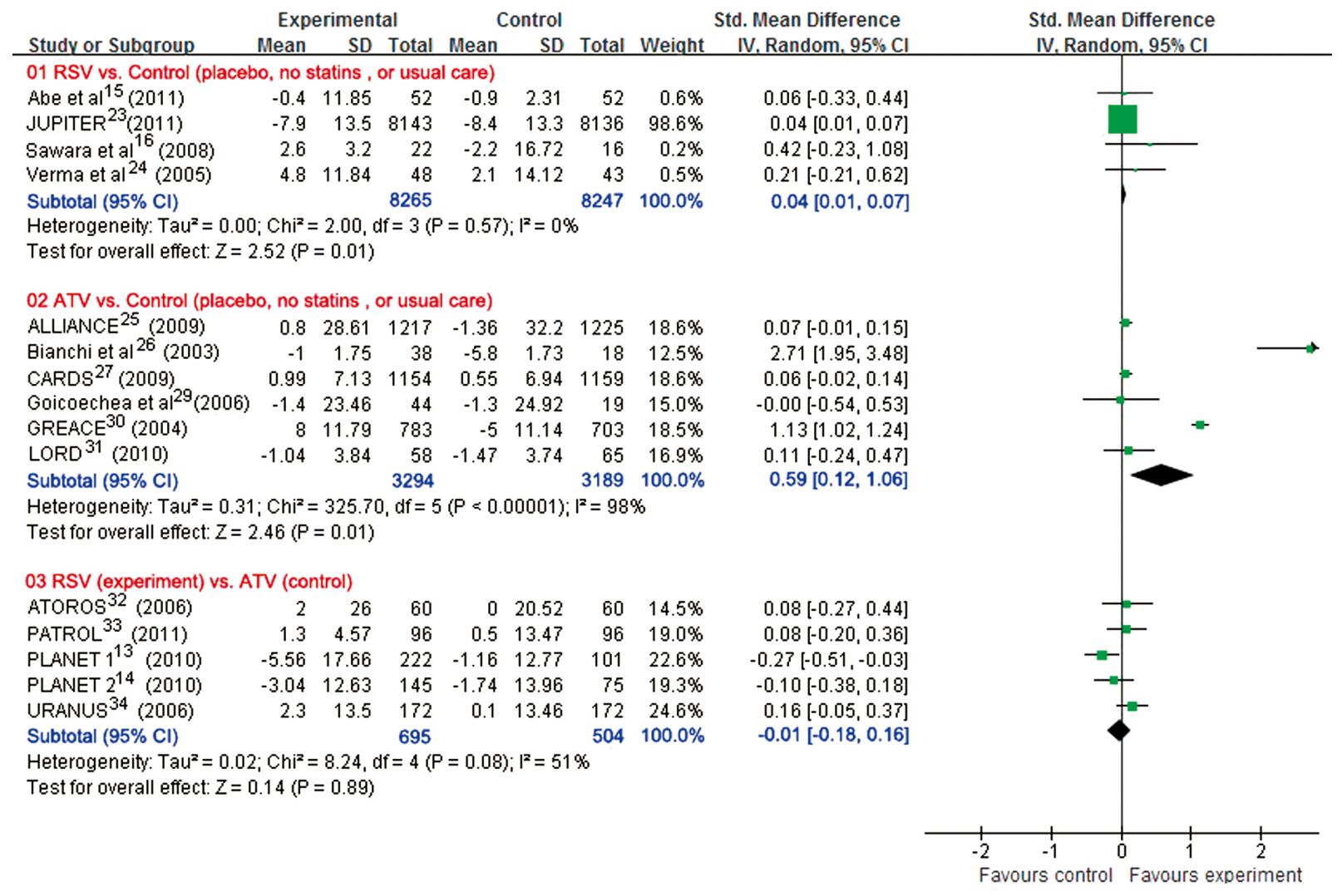

Figure 2. Changes in the standardized (Std.) mean differences of glomerular filtration rate from baseline to follow-up for RSV vs. control (placebo, no statins, usual care), ATV vs. control (placebo, no statins, usual care), and RSV vs. ATV. ATV, atorvastatin; Cl, confidence interval; RSV, rosuvastatin.

line and final data were available, we imputed the mean and SD of the change from baseline according to the Cochrane Handbook. ${ }^{18}$ We obtained the mean change by subtracting the final mean from the baseline mean. ${ }^{18}$ The missing SD was calculated on the basis of reported P-values, if available. ${ }^{18}$ When P-value was not provided, we imputed the missing SD by using the correlation coefficient obtained from other include trials. ${ }^{18}$ We replaced missing mean with median, and missing SD with the width of interquartile range divided by 1.35. ${ }^{19}$ The SMD, which expresses the size of the difference in means in each trial relative to the variability observed in that trial, and the $95 \%$ confidence interval (CI) were measured considering the different units of reported data $(\mathrm{ml} / \mathrm{min}$, $\mathrm{ml} \cdot \mathrm{min}^{-1} \cdot 1.73 \mathrm{~m}^{-2}$, and $\mathrm{ml} \cdot \mathrm{min}^{-1} \cdot$ year $^{-1}$ ). We undertook sensitivity analysis to test the impact of imputation.

For the treatment effect on proteinuria, we used the final data to decrease the bias because the raw data were insufficient and transformation of these data might cause huge errors. Proteinuria was measured via 24-h urine collection and urinary ACR. Although it was difficult to convert these 2 measurements, there was a linear correlation between them. ${ }^{20} \mathrm{We}$ therefore used the ratio of means (ROM) as the treatment effects to summarize the different measurement units. ${ }^{21}$ Moreover, the distribution of proteinuria data was highly skewed, suggesting a logarithmic transformation of the data before analysis. We therefore analyzed the log-transformed data and then reverse transformed to the original scale to obtain ROM (the ratio of the average treatment effect in the experimental group to the control groups).

We assessed statistical heterogeneity between included trials using the $\mathrm{I}^{2}$ statistic. ${ }^{22}$ We pooled the results using a random-effects model instead of a fixed-effects model considering the differences expected between studies (clinical population, doses of RSV and ATV). Publication bias is represented graphically with funnel plots.

All statistical analysis was performed using Review Manager 5.0.25. Statistical significance was set at $\mathrm{P}<0.05$.

\section{Sensitivity Analysis}

We tried different values of correlation coefficients to assess the impact of the imputation for the missing SD. We conducted another sensitivity analysis by pooling the results of GFR and proteinuria using both a random-effects model and a fixed-effects model to estimate the change of effect size. We did additional sensitivity analysis to measure the SMD of proteinuria, and observed whether it was consistent with ROM.

\section{Results}

\section{Search Results}

The literature search yielded 408 articles from which we identified 16 randomized controlled trials for inclusion (Figure 1). ${ }^{13-16,23-34}$ Four trials compared RSV with control, ${ }^{15,16,23,24} 7$ trials compared ATV with control, ${ }^{25-31}$ and 5 trials compared RSV with ATV. ${ }^{13,14,32-34}$ In total, 24,278 individuals were enrolled: for 24,194 of whom the outcomes of 


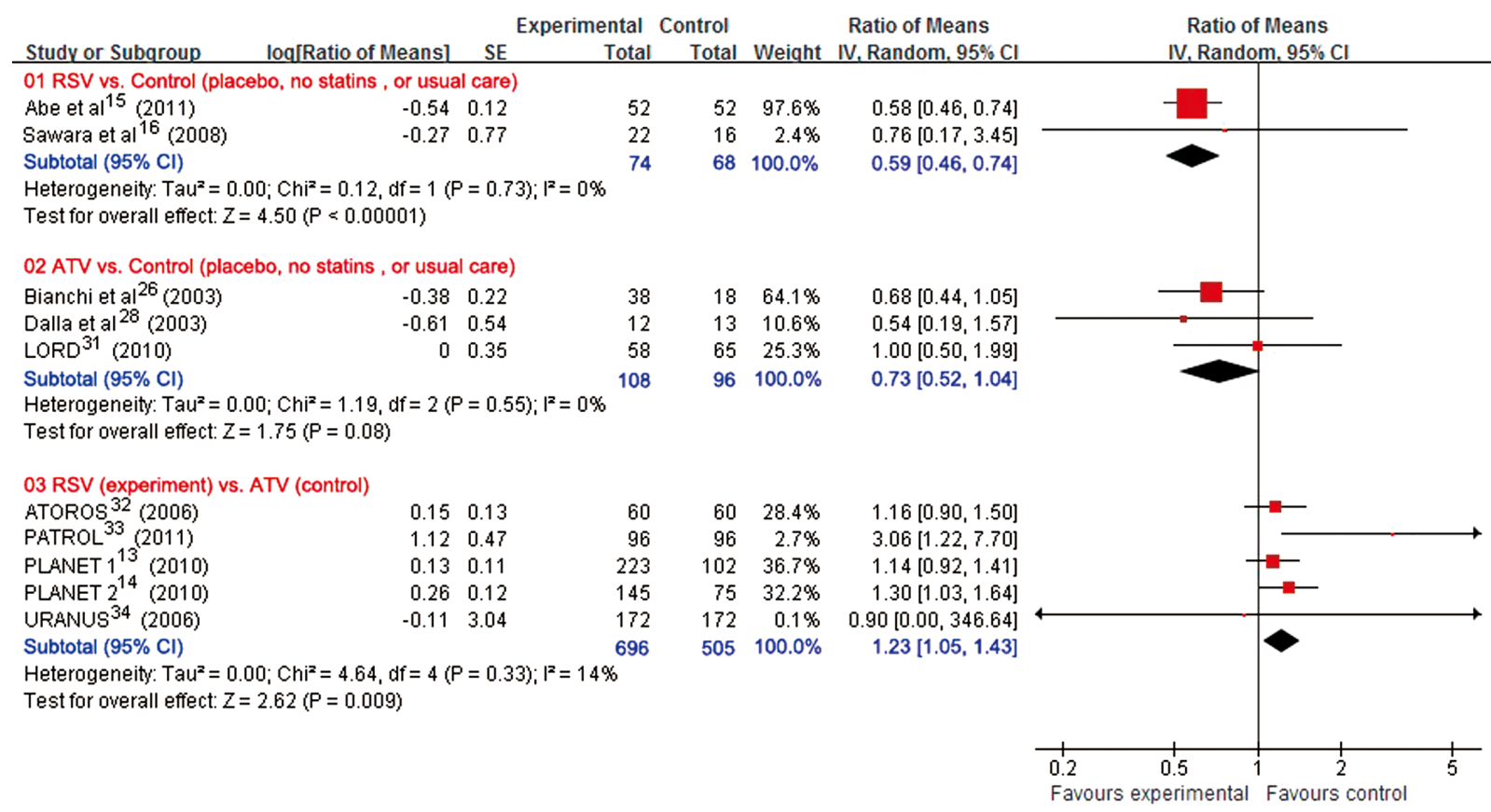

Figure 3. Ratio of means for RSV vs. control (placebo, no statins, usual care), ATV vs. control (placebo, no statins, usual care), and RSV vs. ATV. ATV, atorvastatin; Cl, confidence interval; RSV, rosuvastatin.

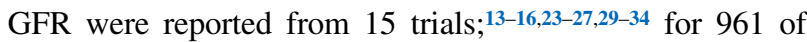
whom PCR/ACR from 5 trials were reported; ${ }^{13-15,32,33}$ and for 586 of whom, UPE were reported from 5 trials. ${ }^{16,26,28,31,34} \mathrm{We}$ excluded most of the studies that did not examine RSV or ATV therapy, that compare RSV or ATV with other statins head-to-head or examine the different dose effect of RSV and ATV, or did not provide adequate outcomes data.

Details of the included studies and baseline characteristics of participants are presented in Tables 1,2. Follow-up of trials ranged from 4 months to 48 months and the mean age of the participants ranged from 53 years to 74 years. All the trials were randomized and controlled and were done in the USA, Japan, Italy, and so on. Six trials enrolled participants with CKD, 5 trials enrolled participants with diabetes mellitus (DM), 2 trials, with CVD and the remaining trials enrolled relatively healthy adults with hypertension or hyperlipidemia. Nine trials measured GFR or proteinuria as a priori outcomes, ${ }^{13-16,24,26,28,29,31} 2$ trials as safety parameters, ${ }^{32,33}$ and the remaining trials as outcomes of post-hoc analysis from major randomized trials.

\section{Trial Quality}

The methodological quality of some enrolled trials was suboptimal. Sequence generation was adequate in 10 trials $(63 \%)$ and unclear in the remainder. Allocation concealment was adequate only in 3 trials (19\%) and unclear in the remainder. Double-blinding was undertaken in 6 trials $(38 \%)$ and the remainder were open-labeled. Incomplete data were addressed in 11 trials $(69 \%)$ and unclear in the remainder. Selective reporting of outcomes was free in 15 trials (94\%) and unclear in $1(6 \%)$. Six trials $(38 \%)$ were free of other bias, 2 trials $(13 \%)$ had bias because of early termination, and the remainder were unclear.

\section{Quantitative Data Analysis}

Effects of RSV and ATV on GFR Compared with control (placebo, no statins, or usual care), both RSV and ATV improved GFR significantly (Figure 2): the change in the SMD of GFR was 0.04 (95\%CI: $0.01-0.07 ; \mathrm{I}^{2}=0 \% ; \mathrm{P}=0.01$ ) for RSV vs. control and 0.59 (95\%CI: $\left.0.12-1.06 ; \mathrm{I}^{2}=98 \% ; \mathrm{P}=0.01\right)$ for ATV vs. control. For the head-to-head comparison of RSV with ATV, the SMD in change from baseline for GFR was -0.01 (95\% CI: -0.18 to $0.16 ; \mathrm{I}^{2}=51 \% ; \mathrm{P}=0.89$ ).

Effects of RSV and ATV on Proteinuria Compared with control (placebo, no statins, or usual care), the ROM was 0.59 (95\%CI: $0.46-0.74 ; \mathrm{I}^{2}=0 \% ; \mathrm{P}<00001$ ) for RSV and 0.73 (95\%CI: $0.52-1.04 ; \mathrm{I}^{2}=0 \% ; \mathrm{P}=0.08$ ) for ATV (Figure 3). The ROM for head-to-head comparison of RSV with ATV was 1.23 (95\%CI: $1.05-1.43 ; \mathrm{I}^{2}=14 \%$; $\mathrm{P}=0.009$ ).

\section{Publication Bias}

We used funnel plots to assess the publication bias. The funnel plots for GFR and proteinuria suggested no evidence of publication bias visually.

\section{Sensitivity Analysis}

When we used different values of correlation coefficients (0.4 and 0.6) to calculate the missing SD, the results of analysis were robust. The pooled treatment effects of RSV and ATV on GFR and proteinuria did not change when we used a fixed-effects model instead of a random-effects model. We also measured the SMD of proteinuria with 2 kinds of units separately: $\mathrm{mg} / \mathrm{day}$ for UPE, and $\mathrm{mg} / \mathrm{gCr}$ for PCR/ACR. The SMD of ACR was 0.19 (95\%CI: 0.05-0.33; $\mathrm{P}=0.008$ ) for RSV compared with ATV head to head, which similarly demonstrated the strength of ATV on proteinuria. 


\section{Discussion}

The present meta-analysis found that both RSV (SMD, 0.04; 95\%CI: 0.01-0.07; P=0.01) and ATV (SMD, 0.59; 95\%CI: 0.12-1.06; $\mathrm{P}=0.01$ ) improved GFR significantly when compared with control groups, and there was no significant difference in the head-to-head comparison. For the treatment effect on proteinuria, RSV was beneficial and the ATV effect was not significant, whereas head-to-head comparison showed that ATV was better than RSV at reducing proteinuria (ROM, 1.23; 95\%CI: $1.05-1.43 ; \mathrm{P}=0.009)$. The cause of these seemingly contradictory results may come from the LORD trial comparing ATV with placebo, which enrolled participants with severe CKD with a low baseline GFR (approximately $30 \mathrm{ml} / \mathrm{min}$ ). When we excluded this trial, ATV treatment became effective for proteinuria compared with control (ROM, 0.66; 95\%CI: 0.44-0.99; $\mathrm{P}=0.04)$. Because the small number of trials restricted our ability to run subgroup analysis, we cannot reach a conclusion as to whether the renoprotective effects of ATV or RSV were different according to the different stages of CKD.

Heterogeneity existed in the comparison of ATV vs. control and in that of RSV vs. ATV for the outcome of GFR. The former could be due to the large treatment effect observed in the Bianchi et al study and the GREACE trial. ${ }^{26,30}$ The SMD in change from baseline for GFR was 0.07 (95\%CI: 0.01-0.12; $\left.\mathrm{I}^{2}=0 \% ; \mathrm{P}=0.02\right)$ when these 2 trials were excluded. The latter could be due to the stronger treatment effect of ATV rather than RSV in the PLANET 1 trial. ${ }^{13}$ When this trial was excluded, the change of SMD for GFR was 0.07 (95\%CI: -0.06 to $\left.0.21 ; \mathrm{I}^{2}=0 \% ; \mathrm{P}=0.29\right)$. Bianchi et al enrolled patients with idiopathic chronic glomerulonephritis who had significant proteinuria, and that trial estimated the effect of ATV on renal function in comparison with no statins after 12 months treatment of angiotensin-converting enzyme inhibitor (ACEI) and/ or angiotensin receptor blocker (ARB). ${ }^{26}$ Previous research has demonstrated that ACEI and ARB delay or prevent the progression of CKD. ${ }^{35}$ For the GREACE trial, we extracted the baseline and final data for participants treated with ATV with structured care in comparison with no statins with usual care ${ }^{30}$ From the PLANET 1 trial, we found that high-dose ATV $(80 \mathrm{mg}$ ) was better than RSV (10 mg and $40 \mathrm{mg}$ ) on GFR and proteinuria in diabetic patients with moderate proteinuria and hyperlipidemia. ${ }^{13}$ This suggests that the heterogeneity could be attributed to the different health condition of participants, cause of CKD, usage of ACEI or ARB, doses of ATV and RSV or any other confounding of study design.

Dyslipidemia is not only a risk factor for CVD, but also a risk factor for the progression of CKD. ${ }^{36}$ Several clinical studies reported that dyslipidemia accelerated the progression of renal function both in CKD patients and in relatively healthy adults. ${ }^{37,38}$ Experimental studies demonstrate that re-absorption of lipoproteins by kidney tubules accelerates tubulo-interstitial inflammation, and that deposition of lipoprotein in the glomerular mesangium also promotes glomerulosclerosis. ${ }^{36}$ The renoprotective effects of statins have been established in experiments $^{39}$ and clinical trials, ${ }^{7,8}$ which showed that these beneficial effects were related to the pleiotropic effects of statins. ${ }^{40}$ These effects result in the attenuation of endothelial dysfunction and oxidative stress, anti-inflammation, anti-proliferation of mesangial cells, and protection of podocyte. ${ }^{41,42}$ Researchers came to similar conclusions about the effects of RSV and ATV on renoprotection. ${ }^{43-46}$

The powerful effects of statins on lipid lowering have been proved, and they were independently associated with the de- crease of all cause mortality and cardiovascular morbidity and mortality in the general population. ${ }^{5,6} \mathrm{CKD}$ patients have a high rate of CVD, which was found to be an independent risk factor for worsening of renal function. ${ }^{47}$ In recent guidelines for the management of dyslipidemia, low-density lipoprotein cholesterol (LDL-C) reduction is recommended as the primary target in order to reduce the CVD risk in CKD subjects (stage 2-4). ${ }^{48}$ Clinical endpoint results for statins, however, are conflicting in CKD patients. The SHARP trial suggested that simvastatin plus ezetimibe reduced the risk of major atherosclerosis events both in dialysis- and in non-dialysis-dependent CKD patients, but that they had no effect on the progression of end-stage renal disease (ESRD). ${ }^{49}$ The CARDS trial and JUPITER trial reported that RSV and ATV reduced the number of major CVD events in non-dialysis-dependent CKD patients, ${ }^{27,50}$ but the AURORA trial and 4D trial did not show this positive effect in dialysis patients. ${ }^{51,52}$ In the present metaanalysis, we have proved the beneficial effects of statins (RSV and ATV) on the parameters of GFR and proteinuria. These 2 parameters both are significant predictors of CVD, ESRD, and mortality. ${ }^{53,54}$ As an established risk factor for progressive renal function loss, ${ }^{55}$ proteinuria or albuminuria is a target in treatment of diabetic kidney disease. ${ }^{56}$ In the general population, proteinuria is an important marker of endothelial injury and an independent risk factor for cardiovascular morbidity and mortality. ${ }^{57}$ A collaborative meta-analysis by Kidney Disease: Improving Global Outcomes (KDIGO) reported that eGFR less than of equal to $60 \mathrm{ml} \cdot \mathrm{min}^{-1} \cdot 1.73 \mathrm{~m}^{-2}$ and ACR less than of equal to $10 \mathrm{mg} / \mathrm{g}$ were independent predictors for mortality in the general population. ${ }^{58}$ To determine whether the subtle changes of GFR and proteinuria, attributed to the renoprotective effects of RSV and ATV, are associated with clinical benefits or not, we need further studies both in patients with and without CKD.

Before the present meta-analysis there were several that discussed the effects of statins on renal outcome. The metaanalysis by Sandhu et al concluded that statins therapy reduced the rate of decline in eGFR by a mean of $1.22 \mathrm{ml} \cdot \mathrm{min}^{-1} \cdot$ year $^{-1}$, and meta-regression found that ATV use was associated with a significantly larger beneficial effect on the rate of decline in eGFR than other statins, but not RSV. ${ }^{9}$ Another meta-analysis of randomized placebo-controlled trials by Douglas et al reported that statins were associated with statistically significant reduction in pathologic level of albuminuria and proteinuria. ${ }^{10}$ The present results are consistent with the previous metaanalysis. To our knowledge, this is the first reported metaanalysis to pool the effects of RSV on renal function and compare RSV with ATV on kidney outcome.

There were several limitations in the present meta-analysis, however. First, considerable variation was found in the patients (CKD, DM, CVD, hyperlipidemia, etc.), intervention (doses of RSV and ATV), outcomes (estimates of GFR and proteinuria), and follow-up (from 4 months to 48 months). These variations may be the cause of heterogeneity between studies on the outcome of GFR. We concluded that ATV can improve GFR (SMD, 0.59; 95\%CI: 0.12-1.06; $\mathrm{I}^{2}=98 \%$; $\mathrm{P}=0.01$ ). Although we used a random-effects model to pool the data, this result should be interpreted with caution. Second, the small number of trials restricted the ability to run subgroup analysis and the statistical power was limited. Meanwhile, the number of high-quality randomized controlled trials was relatively low. Third, in the comparison of RSV vs. control, the sample size was unbalanced among the trials. Fourth, given the different kinds of units, we used relative effect size (SMD and ROM) to measure the treatment effects, 
which should be interpreted with caution. Finally, although we searched several databases and included 2 studies from the ClinicalTrials.gov website, ${ }^{13,14}$ the possibility of publication bias still exists. Outcome reporting bias was also inevitable because we found that several trials reported baseline GFR or proteinuria but not final data. ${ }^{27}$

The present meta-analysis suggests that both RSV and ATV improve GFR, and that ATV may be more effective on reducing proteinuria than RSV. The results should be confirmed, however, by further larger, high-quality, multiple-center studies with a longer follow-up. Head-to-head studies of RSV vs. ATV that measure GFR and proteinuria as a priori efficacy outcomes but not potential adverse events are needed. Although the protective effects of RSV and ATV on kidney outcome have been proved in the present meta-analysis, the clinical benefits of these subtle changes still need to be studied in patients with normal kidney function and with impaired renal function at different stages. In other words, further trials are required to clarify the roles of RSV and ATV both on renal function and on the composite clinic endpoint of death, CVD, progression of ESRD, and doubling of serum creatinine.

\section{Acknowledgments}

This study was supported by the National 973 Basic Research program (no.2009CB521904), a grant of Natural Science Foundation of Shandong Province (Y2007C074) and Independent Innovation Foundation of Shandong University (no.2009DX004).

\section{Disclosures}

Grants: National 973 Basic Research program, grant of Natural Science Foundation of Shandong Province and Independent Innovation Foundation of Shandong University.

\section{References}

1. Jones CA, McQuillan GM, Kusek JW, Eberhardt MS, Herman WH, Coresh J, et al. Serum creatinine levels in the US population: Third National Health and Nutrition Examination Survey. Am J Kidney Dis 1998; 32: 992-999.

2. Foley RN, Collins AJ. End-stage renal disease in the United States: An update from the United States Renal Data System. J Am Soc Nephrol 2007; 18: 2644-2648.

3. Foley RN, Parfrey PS, Sarnak MJ. Clinical epidemiology of cardiovascular disease in chronic renal disease. Am J Kidney Dis 1998; 32: S112-S119.

4. Jungers P, Massy ZA, Nguyen Khoa T, Fumeron C, Labrunie M, Lacour B, et al. Incidence and risk factors of atherosclerotic cardiovascular accidents in predialysis chronic renal failure patients: A prospective study. Nephrol Dial Transplant 1997; 12: 2597-2602.

5. Kong SX, Crawford SY, Gandhi SK, Seeger JD, Schumock GT, Lam $\mathrm{NP}$, et al. Efficacy of 3-hydroxy-3-methylglutaryl coenzyme a reductase inhibitors in the treatment of patients with hypercholesterolemia: A meta-analysis of clinical trials. Clin Ther 1997; 19: 778-797.

6. Hebert PR, Gaziano JM, Chan KS, Hennekens CH. Cholesterol lowering with statin drugs, risk of stroke, and total mortality: An overview of randomized trials. JAMA 1997; 278: 313-321.

7. Lee TM, Lin MS, Tsai CH, Chang NC. Add-on and withdrawal effect of pravastatin on proteinuria in hypertensive patients treated with AT receptor blockers. Kidney Int 2005; 68: 779-787.

8. Buemi M, Allegra A, Corica F, Aloisi C, Giacobbe M, Pettinato G, et al. Effect of fluvastatin on proteinuria in patients with immunoglobulin A nephropathy. Clin Pharmacol Ther 2000; 67: 427-431.

9. Sandhu S, Wiebe N, Fried LF, Tonelli M. Statins for improving renal outcomes: A meta-analysis. J Am Soc Nephrol 2006; 17: 2006-2016.

10. Douglas K, O'Malley PG, Jackson JL. Meta-analysis: The effect of statins on albuminuria. Ann Intern Med 2006; 145: 117-124.

11. Strippoli GF, Navaneethan SD, Johnson DW, Perkovic V, Pellegrini F, Nicolucci A, et al. Effects of statins in patients with chronic kidney disease: Meta-analysis and meta-regression of randomised controlled trials. BMJ 2008; 336: 645-651.

12. Navaneethan SD, Pansini F, Perkovic V, Manno C, Pellegrini F, Johnson DW, et al. HMG CoA reductase inhibitors (statins) for people with chronic kidney disease not requiring dialysis. Cochrane Data- base Syst Rev 2009; (2): CD007784.

13. ClinicalTrials.gov. PLANET I: Prospective evaluation of proteinuria and renal function in diabetic patients with progressive renal disease. http://clinicaltrials.gov/ct2/show/NCT00296374?term=PLANET+1 \&rank=1 (accessed March 3, 2010)

14. ClinicalTrials.gov. PLANET II: Prospective evaluation of proteinuria and renal function in non-diabetic patients with progressive renal disease. http://clinicaltrials.gov/ct2/show/NCT00296400?term_ planet\&rank_1 (accessed March 22, 2010).

15. Abe M, Maruyama N, Okada K, Matsumoto S, Matsumoto K, Soma M. Effects of lipid-lowering therapy with rosuvastatin on kidney function and oxidative stress in patients with diabetic nephropathy. J Atheroscler Thromb 2011; 18: 1018-1028.

16. Sawara Y, Takei T, Uchida K, Ogawa T, Yoshida T, Tsuchiya K, et al. Effects of lipid-lowering therapy with rosuvastatin on atherosclerotic burden in patients with chronic kidney disease. Intern Med 2008; 47: 1505-1510.

17. Higgins JP, Altman DG, Sterne JA, editors. Assessing risk of bias in included studies. In: Higgins JP, Green S, editors. Cochrane handbook for systematic reviews of interventions, version 5.1.0 (updated March 2011). Cochrane Collaboration, 2011 (available from www. cochrane-handbook.org).

18. Higgins JP, Deeks JJ, editors. Selecting studies and collecting data. In: Higgins JP, Green S, editors. Cochrane handbook for systematic reviews of interventions, version 5.1.0 (updated March 2011). Cochrane Collaboration, 2011 (available from www.cochrane-handbook.org).

19. Hozo SP, Djulbegovic B, Hozo I. Estimating the mean and variance from the median, range, and the size of a sample. BMC Med Res Methodol 2005; 5: 13 .

20. Ginsberg JM, Chang BS, Matarese RA, Garella S. Use of single voided urine samples to estimate quantitative proteinuria. $N$ Engl $J$ Med 1983; 309: 1543-1546.

21. Friedrich JO, Adhikari NK, Beyene J. The ratio of means method as an alternative to mean differences for analyzing continuous outcome variables in meta-analysis: A simulation study. BMC Med Res Methodol 2008; 8: 32.

22. Higgins JP, Thompson SG, Deeks JJ, Altman DG. Measuring inconsistency in meta-analyses. BMJ 2003; 327: 557-560.

23. Vidt DG, Ridker PM, Monyak JT, Schreiber MJ, Cressman MD. Longitudinal assessment of estimated glomerular filtration rate in apparently healthy adults: A post hoc analysis from the JUPITER study (justification for the use of statins in prevention: An intervention trial evaluating rosuvastatin). Clin Ther 2011; 33: 717-725.

24. Verma A, Ranganna KM, Reddy RS, Verma M, Gordon NF. Effect of rosuvastatin on C-reactive protein and renal function in patients with chronic kidney disease. Am J Cardiol 2005; 96: 1290-1292.

25. Koren MJ, Davidson MH, Wilson DJ, Fayyad RS, Zuckerman A, Reed DP. Focused atorvastatin therapy in managed-care patients with coronary heart disease and CKD. Am J Kidney Dis 2009; 53: $741-750$.

26. Bianchi S, Bigazzi R, Caiazza A, Campese VM. A controlled, prospective study of the effects of atorvastatin on proteinuria and progression of kidney disease. Am J Kidney Dis 2003; 41: 565-570.

27. Colhoun HM, Betteridge DJ, Durrington PN, Hitman GA, Neil HA, Livingstone SJ, et al. Effects of atorvastatin on kidney outcomes and cardiovascular disease in patients with diabetes: An analysis from the Collaborative Atorvastatin Diabetes Study (CARDS). Am J Kidney Dis 2009; 54: 810-819.

28. Dalla Nora E, Passaro A, Zamboni PF, Calzoni F, Fellin R, Solini A. Atorvastatin improves metabolic control and endothelial function in Type 2 diabetic patients: A placebo-controlled study. J Endocrinol Invest 2003; 26: 73-78.

29. Goicoechea M, de Vinuesa SG, Lahera V, Cachofeiro V, GomezCampdera F, Vega A, et al. Effects of atorvastatin on inflammatory and fibrinolytic parameters in patients with chronic kidney disease. J Am Soc Nephrol 2006; 17: S231-S235.

30. Athyros VG, Mikhailidis DP, Papageorgiou AA, Symeonidis AN, Pehlivanidis AN, Bouloukos VI, et al. The effect of statins versus untreated dyslipidaemia on renal function in patients with coronary heart disease: A subgroup analysis of the Greek atorvastatin and coronary heart disease evaluation (GREACE) study. J Clin Pathol 2004; 57: 728-734.

31. Fassett RG, Robertson IK, Ball MJ, Geraghty DP, Coombes JS. Effect of atorvastatin on kidney function in chronic kidney disease: A randomised double-blind placebo-controlled trial. Atherosclerosis 2010; 213: 218-224.

32. Milionis HJ, Rizos E, Kostapanos M, Filippatos TD, Gazi IF, Ganotakis ES, et al. Treating to target patients with primary hyperlipidaemia: Comparison of the effects of ATOrvastatin and ROSuv- 
astatin (the ATOROS study). Curr Med Res Opin 2006; 22: $1123-$ 1131.

33. Saku K, Zhang B, Noda K. Randomized head-to-head comparison of pitavastatin, atorvastatin, and rosuvastatin for safety and efficacy (quantity and quality of LDL): The PATROL trial. Circ J 2011; 75: $1493-1505$.

34. Sorof J, Berne C, Siewert-Delle A, Jorgensen L, Sager P. Effect of rosuvastatin or atorvastatin on urinary albumin excretion and renal function in type 2 diabetic patients. Diabetes Res Clin Pract 2006; 72: $81-87$.

35. Maschio G, Alberti D, Janin G, Locatelli F, Mann JF, Motolese M, et al. Effect of the angiotensin-converting-enzyme inhibitor benazepril on the progression of chronic renal insufficiency: The Angiotensin-Converting-Enzyme Inhibition in Progressive Renal Insufficiency Study Group. N Engl J Med 1996; 334: 939-945.

36. Romayne Kurukulasuriya L, Athappan G, Saab G, Whaley Connell A, Sowers JR. HMG CoA reductase inhibitors and renoprotection: The weight of the evidence. Ther Adv Cardiovasc Dis 2007; 1: 4959.

37. Samuelsson O, Mulec H, Knight-Gibson C, Attman PO, Kron B, Larsson R, et al. Lipoprotein abnormalities are associated with increased rate of progression of human chronic renal insufficiency. Nephrol Dial Transplant 1997; 12: 1908-1915.

38. Schaeffner ES, Kurth T, Curhan GC, Glynn RJ, Rexrode KM, Baigent $\mathrm{C}$, et al. Cholesterol and the risk of renal dysfunction in apparently healthy men. J Am Soc Nephrol 2003; 14: 2084-2091.

39. Yoshimura A, Nemoto T, Sugenoya Y, Inui K, Watanabe S, Inoue Y, et al. Effect of simvastatin on proliferative nephritis and cell-cycle protein expression. Kidney Int Suppl 1999; 71: S84-S87.

40. Zhou Q, Liao JK. Pleiotropic effects of statins: Basic research and clinical perspectives. Circ J 2010; 74: 818-826.

41. Amann K, Benz K. Statins: Beyond lipids in CKD. Nephrol Dial Transplant 2011; 26: 407-410.

42. Fried LF. Effects of HMG-CoA reductase inhibitors (statins) on progression of kidney disease. Kidney Int 2008; 74: 571-576.

43. Whaley-Connell A, DeMarco VG, Lastra G, Manrique C, Nistala R, Cooper SA, et al. Insulin resistance, oxidative stress, and podocyte injury: Role of rosuvastatin modulation of filtration barrier injury. Am J Nephrol 2008; 28: 67-75.

44. Cormack-Aboud FC, Brinkkoetter PT, Pippin JW, Shankland SJ, Durvasula RV. Rosuvastatin protects against podocyte apoptosis in vitro. Nephrol Dial Transplant 2009; 24: 404-412.

45. Zhou MS, Schuman IH, Jaimes EA, Raij L. Renoprotection by statins is linked to a decrease in renal oxidative stress, TGF-beta, and fibronectin with concomitant increase in nitric oxide bioavailability. Am J Physiol Renal Physiol 2008; 295: F53-F59.

46. Eller P, Eller K, Wolf AM, Reinstadler SJ, Tagwerker A, Patsch JR, et al. Atorvastatin attenuates murine anti-glomerular basement membrane glomerulonephritis. Kidney Int 2010; 77: 428-435.

47. Kiyosue A, Hirata Y, Ando J, Fujita H, Morita T, Takahashi M, et al. Relationship between renal dysfunction and severity of coronary artery disease in Japanese patients. Circ J 2010; 74: 786-791.

48. Reiner Z, Catapano AL, De Backer G, Graham I, Taskinen MR, Wiklund O, et al. ESC/EAS Guidelines for the management of dyslipidaemias. Rev Esp Cardiol 2011; 64: 1168e1-1168e60.

49. Baigent C, Landray MJ, Reith C, Emberson J, Wheeler DC, Tomson $\mathrm{C}$, et al. The effects of lowering LDL cholesterol with simvastatin plus ezetimibe in patients with chronic kidney disease (Study of Heart and Renal Protection): A randomised placebo-controlled trial. Lancet 2011; 377: 2181-2192.

50. Ridker PM, MacFadyen J, Cressman M, Glynn RJ. Efficacy of rosuvastatin among men and women with moderate chronic kidney disease and elevated high-sensitivity C-reactive protein: A secondary analysis from the JUPITER (Justification for the Use of Statins in Prevention-an Intervention Trial Evaluating Rosuvastatin) trial. J Am Coll Cardiol 2010; 55: 1266-1273.

51. Fellstrom BC, Jardine AG, Schmieder RE, Holdaas H, Bannister K, Beutler J, et al. Rosuvastatin and cardiovascular events in patients undergoing hemodialysis. N Engl J Med 2009; 360: 1395-1407.

52. Wanner C, Krane V, Marz W, Olschewski M, Mann JF, Ruf G, et al. Atorvastatin in patients with type 2 diabetes mellitus undergoing hemodialysis. N Engl J Med 2005; 353: 238-248.

53. K/DOQI clinical practice guidelines for chronic kidney disease: Evaluation, classification, and stratification. Am J Kidney Dis 2002; 39: $\mathrm{S} 1-\mathrm{S} 266$.

54. Hamaguchi S, Kinugawa S, Goto D, Tsuchihashi-Makaya M, Yokota T, Yamada S, et al. Predictors of long-term adverse outcomes in elderly patients over 80 years hospitalized with heart failure: A report from the Japanese Cardiac Registry of Heart Failure in Cardiology (JCARE-CARD). Circ J 2011; 75: 2403-2410.

55. Keane WF, Brenner BM, de Zeeuw D, Grunfeld JP, McGill J, Mitch WE, et al. The risk of developing end-stage renal disease in patients with type 2 diabetes and nephropathy: The RENAAL study. Kidney Int 2003; 63: 1499-1507.

56. KDOQI Clinical Practice Guidelines and Clinical Practice Recommendations for Diabetes and Chronic Kidney Disease. Am J Kidney Dis 2007; 49: S12-S154.

57. Hillege HL, Fidler V, Diercks GF, van Gilst WH, de Zeeuw D, van Veldhuisen DJ, et al. Urinary albumin excretion predicts cardiovascular and noncardiovascular mortality in general population. Circulation 2002; 106: 1777-1782.

58. Matsushita K, van der Velde M, Astor BC, Woodward M, Levey AS, de Jong PE, et al. Association of estimated glomerular filtration rate and albuminuria with all-cause and cardiovascular mortality in general population cohorts: A collaborative meta-analysis. Lancet 2010; 375: $2073-2081$.

\section{Supplemental Files}

Supplemental File 1

Figure S1. Funnel plots for included studies in the meta-analysis of glomerular filtration rate show the standardized mean differences (SMD) vs. the standard error (SE) of SMD.

Figure S2. Funnel plots for included studies in the meta-analysis of proteinuria show the ratio of means (ROM) vs. the standard error (SE) for the logarithm of ROM.

Figure S3. Changes in the standardized (Std.) mean differences of glomerular filtration rate when we used correlation coefficient $(\mathrm{r}=0.4)$ to impute the missing SDs.

Figure S4. Changes in the standardized (Std.) mean differences of glomerular filtration rate when we used correlation coefficient $(\mathrm{r}=0.6)$ to impute the missing SDs.

Figure S5. Changes in the standardized (Std.) mean difference of glomerular filtration rate with fixed-effects model.

Figure S6. Ratio of means of proteinuria with fixed-effects model.

Figure S7. Standardized (Std.) mean differences of proteinuria measured by urinary protein excretion.

Figure S8. Standardized (Std.) mean differences of proteinuria measured by albumin-to-creatinine ratio or protein-to-creatinine ratio.

Please find supplemental file(s);

http://dx.doi.org/10.1253/circj.CJ-11-1385 